\title{
Fusion research to face "make or break' demands from US Congress
}

\begin{abstract}
Washington. Arguments over the US fusion research programme are likely to reach record temperatures in this summer's budget debates in Congress, when environmentalist groups trying to kill the programme are expected to clash with proponents arguing that it needs to expand in order to reach a critical mass.
\end{abstract}

At stake will be not only the future of the \$650-million Tokamak Physics Experiment (TPX) planned for the Princeton Plasma Physics Laboratory (PPPL) in New Jersey, but also the fate of the \$10-billion International Thermonuclear Experimental Reactor (ITER) programme, now at the engineering design stage.

Senator Bennett Johnston (Democrat, Louisiana), chairman of the appropriations subcommittee that holds the purse-strings on the Department of Energy's (DoE's) fusion research, has threatened to bring down the shutters on the whole programme unless he gets a firm commitment from the administration to the construction of ITER.

In the light of the Superconducting Super Collider fiasco last year, Johnston wants both Congress and the administration to face up squarely to the issue of funding the US share of ITER's construction. Otherwise, he says, the US domestic fusion programme — including TPX — will be a waste of time.

Johnston wants the administration to act earlier than is currently being planned, and formally to invite its international partners - Europe, Japan and Russia - to commit themselves to the construction phase of ITER. The White House Office of Science and Technology Policy and officials at the DoE are working on a response.

Johnston's all-or-nothing stance reflects a widespread view both in and outside Washington that the fusion programme, whose budget has fallen steadily in real terms from a peak in 1977, is now spread too thinly to achieve its ambitious goals.

Another view is that the big fusion machines such as TPX and ITER are a waste of money, and that an energy source whose proponents admit will not become commercially viable until well into the next century does not deserve the largest single share of the energy research budget.

This position is likely to gather support as environmental lobby groups, until now occupied in cutting back the US fission research programme, switch their attention to fusion.
The Clinton administration was generous to fusion in its recent budget proposals, suggesting an increase from $\$ 344$ million to $\$ 373$ million next year, while other energy programmes are being cut. The largest elements are $\$ 77$ million for research and construction of TPX, and $\$ 69$ million for ITER design work, while research facilities at San Diego and the Massachusetts Institute of Technology share $\$ 67$ million for basic research.

says Brown. "If the administration doesn't give a very strong indication of support, the project is going to die a natural death."

At the Princeton Plasma Physics Laboratory, positive results from a series of fusion experiments that have been running since December at the Tokamak Fusion Test Reactor (TFTR) have failed to allay concern about what will happen when the facility shuts this autumn. The reactor is due to be decontaminated and rebuilt as the TPX; but the physics team at Princeton will face a long wait before the new facility starts to produce any data.

The TPX would need around $\$ 120$ million for construction in both 1996 and 1997 to be completed on schedule in 1999. Energy department officials admit they cannot see where this money will come from. So the project, if it does proceed, faces flat funding, increasing overall costs and delaying completion.

Yet the United States will not be able to choose between TPX and ITER. "They answer very different experimental ques-

The five-year ITER design phase is being conducted jointly on three sites - near Munich, in Tokyo and in San Diego, California - and is due for completion in 1998. The partners are expected to sign a protocol next month to confirm their commitment to the end of that phase of the process, opening the way for discussions on the thorny question of where ITER should actually be built. The engineers want that agreed by 1996 .

The siting decision will not be easy. If Russia is unable to contribute, the host country is likely to have to pay an extra share which may amount to half the costs.

Some physicists fear that Europe, Japan and the United States may end up playing an embarrassing game of pass-the-parcel with this expensive proposition. The 'winner' will then have to cope with the prospect of flagging political support in the 'losing' countries.

A bill already introduced by Johnston and passed in the Senate says that, if plans for ITER falter, then the energy secretary must cut back the domestic programme to $\$ 50$ million a year. In the House of Representatives, George Brown (Democrat, California) is expected to introduce a parallel fusion bill next month; although the two differ on tactics, both Johnston and Brown are determined to extract a cast-iron commitment from the administration to ITER. "If we are going to proceed we need to establish some undertakings in the very near future,' tions," says Anne Davies, director of the Office of Fusion Energy at the energy department.

Some critics contend that TPX, ITER and other fusion experiments based on the Russian tokamak design are misdirected. "They've shut out competing approaches," says Arjun Makhijani of the Institute for Energy and Environmental Research in Takoma Park, Maryland. Makhijani suggests that more basic plasma physics research could provide less problematic solutions than those to be tested at ITER.

But Paul Rutherford, an associate research director at PPPL and chair of ITER's technical advisory panel, says that other concepts "have been tried and failed". The triumph of the tokamak, he says, has been "a matter of survival of the fittest".

Back in 1975, fusion experiments could yield just one-tenth of a watt of power out from $200 \mathrm{~kW}$ in, says Dale Meade, deputy director of PPPL. Progress since then has culminated in the recent experiments at PPPL, producing one-third as much energy out as went in

ITER is designed to be fifteen times better than that, reaching the 'ignition' point at which 20 per cent of energy output is carried by alpha particles, sufficient to sustain the fusion reaction. The remaining 80 per cent of energy output is carried out of the reaction by neutrons, and could be used to generate heat and electricity.

Colin Macilwain 